\title{
Seasonal patterns of habitat use by insectivorous bats in a subtropical African agro-ecosystem dominated by macadamia orchards
}

\author{
Peter John Taylor ${ }^{1 *}$, Ara Monadjem ${ }^{2,3}$ and Jacobus Nicolaas Steyn ${ }^{1}$ \\ ${ }^{1}$ Department of Ecology \& Resource Management, School of Environmental Sciences, University of Venda, P. Bag X5050, Thohoyandou, O950, \\ South Africa, ${ }^{2}$ Department of Biological Sciences, University of Swaziland, Private Bag 4, Kwaluseni, Swaziland and ${ }^{3}$ Department of Zoology E \\ Entomology, Mammal Research Institute, University of Pretoria, Private Bag 20, Hatfield, O028, Pretoria, South Africa
}

\section{Abstract}

We report on acoustic surveys of insectivorous bats conducted during seven months of the year using ANABAT recordings in two habitats (macadamia orchards and adjacent riparian bush) in a subtropical agroecosystem in northern South Africa. We defined two functional foraging groups of bats based on their echolocation calls: (i) open-air foragers (family Molossidae) having narrow-band, low-frequency, low duty cycle calls; and (ii) clutter-edge foragers (families Miniopteridae and Vespertilionidae), having broad-band, higher frequency, low duty cycle calls. Bat activity (number of bat passes) was not significantly influenced by habitat. Total bat activity and activity of both functional groups varied significantly between seasons, being highest in summer and autumn (coinciding with annual peaks in numbers of Twin spotted (Bathycoelia natalicola) and Green (Nezara spp) Stinkbugs, order Heteroptera, family Pentatomidae, and Macadamia Nut Borer moths, Cryptophlebia ombrodelta) and lower in winter and spring. No significant effect of moon phase was detected, either on total activity or activity of the two functional groups. We postulate that the significant pattern of seasonality of commuting and/or foraging activity of bats in macadamia orchards (which is more marked in open-air foragers) may be driven by the seasonal abundance of pest insects such as stinkbugs and Macadamia Nut Borer moths.

Key words: bat activity, habitat, macadamias, moon phase, season, stinkbugs

*Correspondence: E-mail: Peter.Taylor@univen.ac.za

\section{Résumé}

Nous rapportons une étude acoustique des chauvessouris insectivores menées pendant sept mois de l'année en utilisant les enregistrements ANABAT dans deux habitats (les vergers de macadamia et la savane adjacente riveraine) dans un agro-écosystème subtropical dans le nord de l'Afrique du Sud. Nous avons défini deux groupes fonctionnels alimentation des chauves-souris en fonction de leurs cris d'e'cholocalisation: 1) les butineuses en plein air (famille Molossidae) ayant les cris "low duty cycle" à bande étroite, de fréquence basse, et 2) les butineuses au bord de l'encombrement (familles Miniopteridae et Vespertilionidae), ayant les cris "high duty cycle” à large bande, de fréquence plus élevée. L'activité (nombre de passages de chauves-souris) n'a pas été significativement influencé par l'habitat. L'activité totale chauve-souris et l'activité des groupes fonctionnels varient considérablement entre les saisons, la plus haute étant en été et en automne (coïncidant avec des pics annuels en nombre de punaises, Bathycoelia natalicola et Nezara spp, ordre Heteroptera, famille Pentatomidae, et les pyrales de noix de macadamia, Cryptophlebia ombrodelta, ordre Lepidotera) et inférieures en hiver et au printemps. Pas d'effet significatif de la phase de lune a été détecté, soit à l'activité totale ou de l'activité des deux groupes fonctionnels. Nous postulons que la tendance significative de la saisonnalité des déplacements et/ou de l'activité de recherche de nourriture des chauves-souris dans les vergers de macadamia (ce qui est plus marquée dans les butineuses en plein air) peut être entraîné par l'abondance saisonnière des insectes ravageurs tels que les punaises et les pyrales de noix de macadamia. 


\section{Introduction}

Bats are important bioindicators whose populations and communities change in response to a range of stressors such as habitat fragmentation and agricultural intensification (Jones et al., 2009). In recent years, an increasing number of ecological studies of bat communities and populations have been carried out in both natural and disturbed ecosystems in Africa (e.g. Fenton et al., 1998; Meyer, Schwarz \& Fahr, 2004; Schoeman, 2006; Monadjem \& Reside, 2008; Schoeman \& Jacobs, 2008; Monadjem et al., 2010a; Schoeman \& Jacobs, 2011; Naidoo, Mackey \& Schoeman, 2011; Noer et al., 2012; Taylor et al., 2012; Schoeman \& Waddington, 2011). Bats provide critical ecosystem services which include consumption of agricultural pests (Kalka, Smith \& Kalko, 2008; Williams-Guillén, Perfecto \& Van der Meer, 2008; Jones et al., 2009; Bohmann et al., 2011; Boyles et al., 2011; Kunz et al., 2011; McCracken et al., 2012), including in macadamia plantations in South Africa. Among other species, stinkbugs (order Heteroptera: families Pentatomidae and Coreidae) have been identified as the major pests of macadamias (Ironside, 1981; Jones \& Caprio, 1992, 1994; Jones, Delate \& Tome, 1992; Vincent et al., 2001). Bats (particularly Molossidae) have been demonstrated to prey on stinkbugs in America (Kunz et al., 2011) and Africa (Bohmann et al., 2011). Given the large volumes of insects consumed by bats, bat predation of pest insects has been shown to have a significant economic benefit to farmers (Cleveland et al., 2006; Boyles et al., 2011; Kunz et al., 2011). However, few studies have quantified this benefit (but see Boyles et al., 2011). In sugar cane plantations in Swaziland, Noer et al. (2012) showed from radiotracking data that bats selectively forage over sugar cane fields, whilst Bohmann et al. (2011) showed from mitochondrial sequences of insects from faecal pellets that two molossid bat species (Chaerephon pumilus and Mops condylurus) feed on insect species such as boring moths (Eldana saccharina and Mythimna phaea) and stinkbugs. There is an urgent need to demonstrate the economic value of bats to agriculture to promote awareness of the need for their conservation.

Using ANABAT bat detectors, we aimed to investigate activity patterns and habitat use of bats in macadamia orchards and adjacent riparian habitat at a farm in the subtropical fruit-growing area of the Levuvhu Valley in Limpopo Province. Given the known presence in macad- amia orchards of a range of nocturnal insect pests such as moths (order Lepidoptera: False Codling Moth, Thaumatotibia (Cryptophlebia) leucotreta, and Macadamia Nut Borer, Cryptophlebia ombrodelta), Shield Stinkbugs (family Pentatomidae, order Heteroptera) and Coconut Stinkbugs (family Coreidae; order Heteroptera), and that different groups of African bat species forage on a range of different insect orders (Monadjem et al., 2010b), we predict that a variety of local bat species should forage in macadamia orchards. We further predict that seasonal variation of foraging activity of bats in macadamia orchards should correspond with the times of the year when major infestations of pest insects are known to occur in local orchards, for example, November to January in C. ombrodelta and generally late summer to autumn in stinkbugs (Schoeman \& Mohlala, in press; and this study: see Results). For stinkbugs in general, and particularly the dominant Twin-Spotted Stinkbug (Bathycoelia natalicola) in the Nelspruit area of South Africa, Schoeman \& Mohlala (in press) recorded a major annual peak in numbers in January and a minor peak in April. The same study demonstrated a major flight peak in Macadamia Nut Borers in late November. Given the markedly cold winters (see Study area, below), we predict that bat activity should be considerably reduced in winter and at lower minimum daily temperatures. Finally, we tested for the effect of moon phase on activity of bats generally, and on different taxonomic/functional groups, as it has been shown that moon phase may significantly alter activity of open-air foraging bats but not bats which forage in clutter. A full moon generally reduces activity of insects as well as bats by rendering them more visible to predators (Meyer, Schwarz \& Fahr, 2004). In our study, we did not acoustically record any clutter-dependent species (such as Rhinolophus spp, Hipposideros spp and Nycteris spp) in macadamia orchards, but we classified bats into two functional groups based on their echolocation calls: (i) open-air foragers (Molossidae) having narrow-band, low duty cycle calls ('quasi-constant-frequency' or QCF); and (ii) clutter-edge foragers (Miniopteridae and Vespertilionidae), having broad-band, low duty cycle calls.

\section{Materials and methods}

\section{Study area}

Portion 28 of the farm Welgevonden number 4LT $(-23.0594 \mathrm{~S} ; 30.07 \mathrm{E})$ is located in the southern foothills 
of the Soutpansberg Range, $20 \mathrm{~km}$ east of the town of Makhado (previously Louis Trichardt), and bordered to the east and south by the Levuvhu Valley subtropical fruitgrowing area which is dominated by extensive monocultures of macadamias, pecan nuts, avocados, bananas and pine and gum plantations. It is bordered to the north by mountains covered predominantly by dense thickets classified as 'Soutpansberg Mountain Bushveld' (Mucina \& Rutherford, 2006) as well as by extensive commercial plantations of gums and pines. Based on data obtained for the study period from a weather station on the farm of D. Alberts, approximately $10 \mathrm{~km}$ from the study area, annual rainfall in the study area was $930 \mathrm{~mm}$ for 2010 and $960 \mathrm{~mm}$ for 2011 and fell mostly between November and April (Fig. 1). Daily maximum temperatures frequently exceed $35^{\circ} \mathrm{C}$ in summer (October to March) but seldom reach $40^{\circ} \mathrm{C}$ and minimum daily summer temperature seldom fall below $15^{\circ} \mathrm{C}$, whereas winters are much colder, with minimum daily temperatures dropping to just over $0^{\circ} \mathrm{C}$ on a few days in June and July and maximum daily temperatures reaching $25^{\circ} \mathrm{C}$. Hourly rainfall, temperature and humidity data were available for the period under study through data provided by D. Alberts from the above-mentioned weather station. We extracted daily minimum temperatures for each night of sampling to enter into the generalized linear models developed to test different activity variables (see below).

\section{Acoustic analyses}

An ANABAT SD1 detector (www.titley.com.au) was used to make recordings of the ultrasonic vocalizations of bats which were stored automatically on an SD memory card and later analysed by the ANALOOK programme (Chris Corben, version 0.3.8.13, http://www.hoarybat.com). The ANABAT system is widely used for bat surveys worldwide and has the advantage of being able to record huge volumes of bat call data automatically and efficiently (O'Farrell, Miller \& Gannon, 1999; Gannon, Sherwin \& Hayamond, 2003; Milne et al., 2004; Monadjem, Reside \& Lumsden, 2007; Monadjem et al., 2010a; Williams-Guillen \& Perfecto, 2011; Skalak, Sherwin \& Brigham, 2012).

Acoustic studies of habitat use in bats should clearly enunciate research assumptions, hypotheses and equipment limitations, and should allow sufficient replication to account for temporal and spatial variation of sampling points (Gannon, Sherwin \& Hayamond, 2003; Skalak, Sherwin \& Brigham, 2012). Following these guidelines, we used a randomized walked-transect sampling protocol to actively record bat echolocation calls with the ANABAT SD1 bat detector during the peak feeding period of bats (for 100 min recording time per night commencing at dusk). To verify the peak activity period of bats, we made ANABAT recordings (with a second ANABAT SD2 recorder calibrated with the ANABAT SD1 detector) from

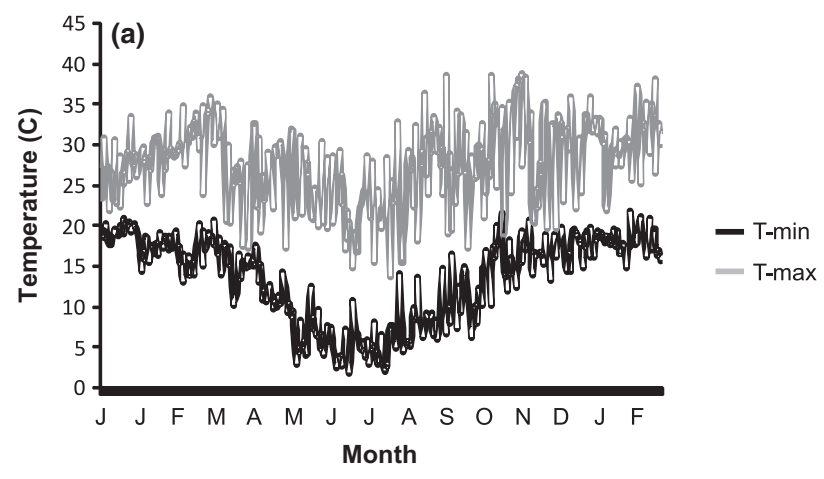

Fig 1 Daily minimum (T-min) and maximum (T-max) temperatures for January 2011 to February 2012 (a) and monthly rainfall for duration of study period from May 2010 to February 2012 (b) on a farm neighbouring the study area (D. Alberts, unpublished data)

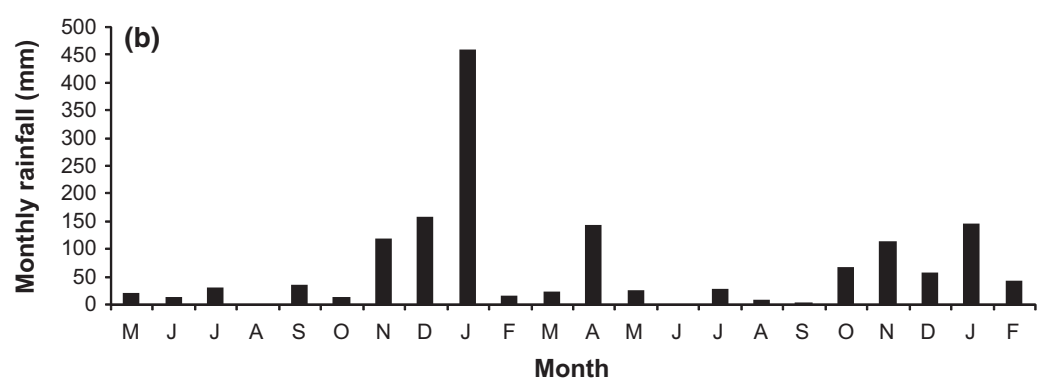


dusk to dawn from a fixed point in the middle of the macadamia orchards on one of the days on which transects were performed (8 February 2012). Using ArcView 3.1 (ESRI), we generated 20 random sites in each of two habitats on the same farm (Farm Welgevonden), macadamia orchards and a neighbouring area of riparian bush. Points were placed randomly within the predefined habitats and set to be at least $30 \mathrm{~m}$ apart from each other and the habitat border (since $30 \mathrm{~m}$ was understood to represent the limit of sensitivity of the detector). GPS points for each site were recorded and used in conjunction with reflective tape markers to locate sites in subsequent sessions. Sites within each of the two habitats were numbered from 1 to 20 . Using a random number generator in Excel, we randomly chose the starting point for each sample session and for each habitat. Sample sessions almost always comprised two consecutive nights although weather or logistical factors resulted in two single-night sessions (in May 2010 and July 2011) and one three-night session (October 2010). We recorded during May, October and November 2010, May, June, July and September 2011 and February 2012. For the purpose of this study, we pooled monthly data between years and assumed that inter-annual variation was not significant (an assumption supported by very similar, high activities recorded in May 2010 and May 2011). Recording commenced at dusk in either the macadamia orchards or riparian bush (the order was also randomly decided for each session). On the first night of each session we sampled ten points in each habitat, with exactly five minutes of recording time per sample point. On the second night, we started with a different habitat and proceeded to sample the remaining ten points in each habitat.

Calls were identified to family based on call duration, bandwidth and frequency at the knee $\left(\mathrm{F}_{\mathrm{K}}\right)$. Based on known data for reference calls for the region (P.J. Taylor, S. Sowler, M.C. Schoeman \& A. Monadjem, unpublished data; Monadjem et al., 2010b), bats belonging to Molossidae were identified as having low frequency calls $\left(\mathrm{F}_{\mathrm{K}}<30 \mathrm{kHz}\right)$ of long duration (typically $\left.>10 \mathrm{~ms}\right)$ and narrow bandwidth $(<10 \mathrm{kHz})$, whereas bats belonging to Vespertilionidae and Miniopteridae were identified by having higher frequency calls $\left(\mathrm{F}_{\mathrm{K}}>30 \mathrm{kHz}\right)$ with shorter duration $(<10 \mathrm{~ms})$ and broader bandwidth $(>20 \mathrm{kHz})$. The presence of Miniopteridae was based on calls having $\mathrm{F}_{\mathrm{K}}$ of 54 to $58 \mathrm{KHz}$, typical for Miniopterus natalensis. On the basis of a recently established ANABAT call library for the region (P.J. Taylor, S. Sowler, M.C. Schoeman \&
A. Monadjem, unpublished data), we were able to identify most calls to probable species; in some cases, species occurrences in the study area could be verified from captures with harp traps or mistnets or from roost searches from farms neighbouring the study area (P.J. Taylor, S. Sowler, M.C. Schoeman \& A. Monadjem, unpublished data). Although not the primary purpose of this article, we nevertheless provide species lists based on acoustic data for the two habitats surveyed in this study. We calculated activity (measured as number of bat passes per $50 \mathrm{~min}$ recording session) for each habitat and sample session. As frequency histograms of bat activity were markedly skewed positively (nonnormal), and since we found evidence for nonconstant variance in total activity and activity of the two functional groups (significant values for Breush-Pagan test) as typical for counts data, we initially fitted the data to generalized linear models using the Poisson distribution. However, as our data were overdispersed (dispersion parameter for global models of different activity variables was three to five times greater than unity), we fitted our data using generalized linear models with both quasi-poisson and negative binomial distributions (see van Hoef \& Boveng, 2007 for discussion of these two common solutions for overdispersion). Since the results in terms of relative performance of models were almost identical, and since the latter is less restrictive and allows conventional use of Aikaike Information Criterion (AIC) values and step-wise regression procedures, we present only the latter here. Statistical analyses were conducted in R2.15.0 (R Development Core Team, Vienna, available at http://www.r-project.org, accessed 17 November 2012). We developed models to test the effect of four different independent predictor variables (habitat, season, minimum daily temperature and moon phase), separately and in combination, on three dependent variables, total bat activity, activity of molossid bats (open-air functional group) and activity of vespertilionid and miniopterid bats (clutter-edge functional group). Models were assessed by examining standardized residuals for linearity, normality, independence and constancy of error variance. In all cases, residual plots conformed closely with assumptions. Final model selection was based on the Aikaike Information Criterion (due to low sample sizes we used the conservative AICc estimate) with the lowest values representing the best model. We also conducted step-wise (backward and forward) regression on global models (with all predictors included) to determine optimal subsets of important predictors based on AICc values. 


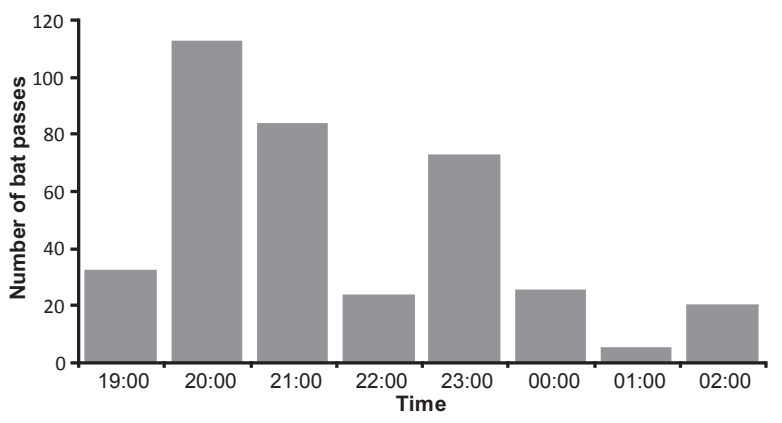

Fig 2 Number of bat passes per hour for one complete night of acoustic recording at a fixed point at Farm Welgevonden on 9 February 2012

\section{Pest insect sampling}

Data on fortnightly captures of two moth species (False Coddling Moth, Thaumatotibia (Cryptophlebia) leucotreta, and Macadamia Nut Borer, C. ombrodelta) were supplied by A. Whyte from commercial pheromone monitoring traps on Springfield Farms which neighboured our study farm, Welgevonden. As part of a separate PHD study by J.N. Steyn, data on monthly numbers of stinkbugs (for the Twin-Spotted Stinkbug Bathycoelia natalicola, and Green Stinkbugs, Nezara spp) were obtained weekly from macadamia orchards on Farm Welgevonden using a mechanical 'knock-down' method whereby four large randomly selected macadamia tree branches were shaken vigorously four times each and all ejected stinkbugs captured and identified. Sampling was done in early mornings when stinkbugs were immobile (at temperatures below $18^{\circ} \mathrm{C}$ ). Whilst data were available from 2011 to 2012, we presented data only from 2011 for comparability with the sampling period for the bat data.

\section{Results}

Based on continuous recordings made throughout one night, activity peaked between 20:00 and 22:00, although it continued throughout the night with a second smaller peak around 23:00 to 00:00 (Fig. 2). Since our walked transects recorded for $100 \mathrm{~min}$ of calls after dusk, and since additional time (approximately $40 \mathrm{~min}$ ) was spent walking between sample points, our sample periods always ended after 22:00. We are therefore confident that we adequately sampled the peak foraging and commuting period of bats.

Acoustic data indicated that at least 14 species of bats occur in the study area, and all but one was active in both macadamia orchards and adjacent riparian habitats

Table 1 Occurrence of different bat species recorded in two habitats at Farm Welgevonden based on acoustic data (15 nights of ANABAT SD1 recordings) and additional observational (roosts) and capture (harp trap and mistnet) data obtained from Welgevonden and two neighbouring farms (reported in detail in P.J. Taylor, S. Sowler, M.C. Schoeman \& A. Monadjem, unpublished data). Identification of species from their calls was based on a library of several frequency and temporal parameters obtained from reference calls in P.J. Taylor, S. Sowler, M.C. Schoeman \& A. Monadjem (unpublished data); for the sake of simplification, results of only one important frequency parameter are shown here (Frequency of the knee, $\mathrm{F}_{\mathrm{KNEE}}$ )

\begin{tabular}{|c|c|c|c|c|}
\hline & $\mathrm{F}_{\mathrm{KNEE}}(\mathrm{kHz})$ & Capture/observation records & Macadamia & Riparian \\
\hline \multicolumn{5}{|l|}{ Family Molossidae: } \\
\hline Mops midas & $14(12-15)$ & Roost & $\mathrm{X}$ & $\mathrm{X}$ \\
\hline Mops condylurus & $30(27-32)$ & Roost, mistnet & $\mathrm{X}$ & $\mathrm{X}$ \\
\hline Chaerephon pumilus & $29(24-31)$ & Roost, mistnet & $\mathrm{X}$ & $\mathrm{X}$ \\
\hline Chaerephon ansorgei & $20(19-22)$ & - & $\mathrm{X}$ & $\mathrm{X}$ \\
\hline Tadarida aegyptiaca & $24(22-26)$ & - & $\mathrm{X}$ & $\mathrm{X}$ \\
\hline \multicolumn{5}{|l|}{ Family Vespertilionidae: } \\
\hline Neoromicia nana & $68(66-70)$ & Harp trap & $\mathrm{X}$ & $\mathrm{X}$ \\
\hline Neoromicia zuluensis & $51(48-56)$ & - & $\mathrm{X}$ & $\mathrm{X}$ \\
\hline Neoromicia capensis & $40(37-42)$ & - & $\mathrm{X}$ & - \\
\hline Pipistrellus hesperidus & $50(45-55)$ & Harp trap & $\mathrm{X}$ & $\mathrm{X}$ \\
\hline Myotis tricolor & $58(48-68)$ & Harp trap & $\mathrm{X}$ & $\mathrm{X}$ \\
\hline Scotophilus dingani & $36(34-37)$ & Roost & $\mathrm{X}$ & $\mathrm{X}$ \\
\hline \multicolumn{5}{|l|}{ Family Miniopteridae: } \\
\hline Miniopterus natalensis & $56(56-57)$ & Harp trap & $\mathrm{X}$ & $\mathrm{X}$ \\
\hline Unknown vespertilionid ( $\mathrm{F}_{\mathrm{KNEE}} 65 \mathrm{kHz}$ ) & 65 & - & $\mathrm{X}$ & $\mathrm{X}$ \\
\hline Unknown (Narrow band, $\mathrm{F}_{\mathrm{KNEE}} 31 \mathrm{kHz}$ ) & 31 & - & $\mathrm{X}$ & $\mathrm{X}$ \\
\hline
\end{tabular}


(Table 1). Additional capture and observational data from neighbouring farms to Welgevonden validated eight of these species and a further three have been captured from the Soutpansberg Range within $100 \mathrm{~km}$ of the study site (P.J. Taylor, S. Sowler, M.C. Schoeman \& A. Monadjem, unpublished data).

Activity of clutter-edge bats (Vespertilionidae/Miniopteridae) was barely significantly $(P<0.05)$ higher in riparian habitats compared with the orchards, and the model employing habitat only had the lowest AICc value, albeit only just lower than the global model (Fig. 3; Table 2). There was no significant effect of habitat for total bat activity or activity of open-air feeders (Molossidae) (Table 2).

On the other hand, activity patterns of bats showed strong temporal patterns. Total activity of bats was highest in February and May for both macadamia orchards and riparian habitats, substantially lower from September to November in macadamia orchards (but less so in riparian habitats), and reduced in June and July for both habitats (Fig. 4). Total activity of all bats and activity of both foraging groups varied significantly with season $(P<0.01$; Table 2). For total bat activity and activity of molossids (open-air feeders), the best model (lowest AICc values) was season alone. In vespertilionid/miniopterid bats (clutteredge feeders), the best model was that involving habitat alone (Table 2). Activity was highest in summer and

Table 2 Results of generalized linear models with negative binomial distribution (AICc scores) in R for total bat activity, activity of Molossidae and activity of Vespertilionidae/Miniopteridae

\begin{tabular}{|c|c|c|c|}
\hline \multirow[b]{2}{*}{ Model } & \multicolumn{3}{|c|}{ AICc values } \\
\hline & $\begin{array}{l}\text { Total } \\
\text { activity }\end{array}$ & $\begin{array}{l}\text { Activity } \\
\text { (Molossidae) }\end{array}$ & $\begin{array}{l}\text { Activity } \\
\text { (Vespertilionidae/ } \\
\text { Miniopteridae) }\end{array}$ \\
\hline $\begin{array}{l}\text { Minimum } \\
\text { temperature }\end{array}$ & 205.9 & 153.9 & 176.9 \\
\hline Habitat & 207.6 & 155.9 & $173.9 *$ \\
\hline Season & $197.9^{* *}$ & $136.7^{* *}$ & $176.9 *$ \\
\hline Moon & 211.2 & 156.2 & 182.0 \\
\hline $\begin{array}{l}\text { Habitat+Season+ } \\
\text { Moon+ }\end{array}$ & $200.3^{* *}$ & $146.9^{* *}$ & $174.8^{* *}$ \\
\hline Min. temp & & & \\
\hline
\end{tabular}

Significance of F-values (ANOVA) indicated by $*(P<0.05)$ and $* *(P<0.01)$. Numbers in bold face represent the model having the lowest AICc value for each variable.

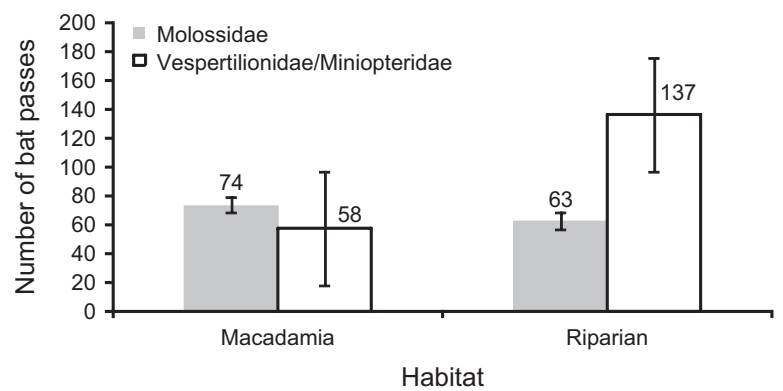

Fig 3 Mean number of bat passes recorded for open-foraging bats (Molossidae) and clutter-edge-foraging bats (Vespertilionidae and Miniopteridae) in macadamia orchards and adjacent riparian bush at Farm Welgevonden. Bars represent standard errors

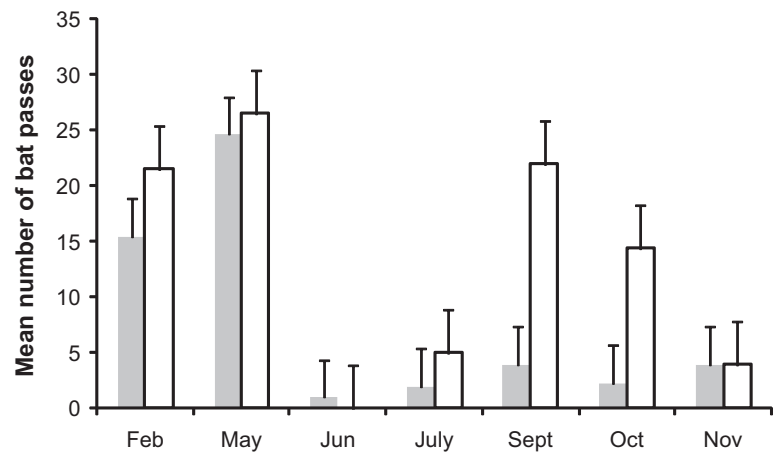

Fig 4 Mean number of bat passes recorded with ANABAT detector at Farm Welgevonden in macadamia orchards (shaded bars) and adjacent riperian bush (open bars) for different months sampled between May 2010 and February 2012. Monthy data were pooled over different years (May, October and November 2010, May, June, July, September 2011 and February 12). Bars indicate standard errors

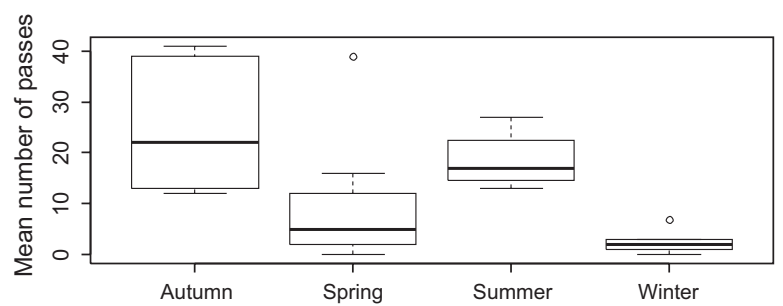

Fig 5 Box and whisker plots showing comparison of bat activity (number of bat passes) per season at Farm Welgevonden. Spring was defined by the months September to November; summer December to February, autumn March to May and winter June to August 
Fig 6 Plots of weekly numbers of false codling moths, Thaumatotibia (Cryptophlebia) leucotreta (FCM: black line) and macadamia nut borers, Cryptophlebia ombrodelta (MNB: grey line) from September 2009 to January 2012 based on pheromone traps placed at a farm (Springfield Farms) adjacent to the study area. Data used with permission of the farm owner, A. Wyte

autumn and lower in winter and spring (Fig. 5). We did not find statistical support for the hypothesis that moon-lit nights might have lower activity than dark-phase nights (Table 2). Although we might have expected a significant decrease of activity at lower temperatures, no statistical evidence was forthcoming for this hypothesis (Table 2).

Stepwise regression (both forward and backward) was carried out on all activity variables. In total activity, the model resulted in a subset containing season and habitat; in molossid bat activity, season and minimum temperature were retained whilst in vespertilionids/miniopterids all four variables were retained (Table 2).

Data from pheromone traps indicated very marked, regular annual population increases in the Macadamia Nut Borer (C. ombrodelta) from December to January, but not in the False Codling Moth (Thaumatotibia (Cryptophlebia) leucotreta) over at least three years (2009/10 to 2011/2; Fig. 6). Populations of the Twin-Spotted Stinkbug (Bathycoelia natalicola) at Welgevonden Farm were very low between April and August, 2011, began to increase in September and reached a peak between October and February before declining in March. Populations of Green Stinkbugs (Nezara spp.) showed a similar annual trend although they only appeared in November (being absent in September and October). After a peak from November to January, numbers decreased in February with a secondary peak in May and June (Fig. 7).

\section{Discussion}

Acoustic data supplemented with capture and observational data indicated the occurrence of at least 14 species of bats in the study area. There did not appear to be any difference in species composition or richness between macadamia orchards and riparian bush. The study area is located in the foothills of the Soutpansberg Range which have been shown to be a regional hotspot of bat species richness (Schoeman et al. in press). The macroecological models of Schoeman et al.(in press) predict that 27 species should occur within the degree-square where the study area was located. A broader study of several farms in the eastern Soutpansberg (within approximately $30 \mathrm{~km}$ radius of the study area; P.J. Taylor, S. Sowler, M.C. Schoeman \& A. Monadjem, unpublished data) demonstrated the occurrence of at least 21 species. Thus, our study underestimated the true diversity but nevertheless indicated that at least $66 \%$ of the local bat community are commuting or foraging in an agricultural landscape dominated by macadamia orchards. This high diversity may be partly due to the close proximity of the Soutpansberg Range and it would be interesting to investigate the effect of increasing distance from the mountains on bat species richness within the extensive commercial subtropical fruit-growing region of the Luvuvhu Valley.

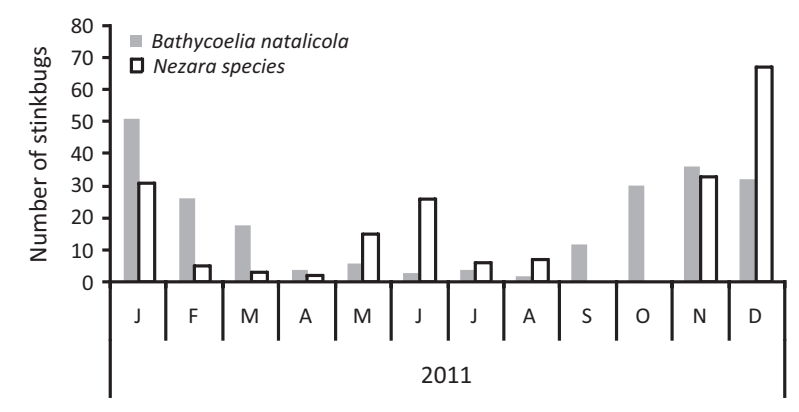

Fig 7 Plot showing monthly numbers of two species of stinkbugs estimated from knock-down sampling at Welgevonden Farm during 2011 
We hypothesized that bat activity in macadamia orchards would correspond with seasonal peaks in insect numbers and particularly those of known pest species. Activity of bats in macadamia orchards and in adjacent natural riparian habitat varied significantly with season, being elevated during February (late summer) and May (autumn). This trend was more marked in macadamia orchards compared with adjacent riparian habitats which showed greater variability in activity estimates. Based on data obtained from a neighbouring macadamia farm, populations of Macadamia Nut Borer moths appear to peak annually around December and January of each year (for 2009/10 and 2010/11), although a longer peak (September to January) was experienced in 2011/12 (Fig. 6). Based on known patterns of stinkbug population cycles in South Africa generally (Schoeman \& Mohlala, in press), as verified from preliminary data for the study area (Fig. 7), stinkbug numbers begin to build up during late spring (October to November) in response to warmer conditions. In both Twin-Spotted and Green Stinkbugs, populations peak during mid-late summer (November to February), although the latter have a shorter peak in summer (November to January) and a secondary peak in May and June. On the whole, these seasonal patterns correspond quite closely to seasonal bat activity patterns, at least in terms of a summer peak in bat activity and stinkbug numbers with a secondary peak of bat activity and Green Stinkbug numbers in autumn (May). However, the high number of stinkbug numbers in June does not correspond with very low bat activity, probably due to very low ambient temperatures experienced in June (Fig. 1).

Although many species of stinkbugs are frequently rather sedentary at night, particularly at colder temperatures, at least two studies have demonstrated conclusively that molossid bats feed frequently on stinkbugs (Bohmann et al., 2011; Kunz et al., 2011). In our study, molossid species were recorded foraging or commuting over macadamia orchards, and molossids showed a significant increase in activity during late summer and autumn when stinkbug numbers reach their annual peaks.

We were surprised that habitat did not have a greater impact on bat activity given its importance in other studies (e.g. Monadjem \& Reside, 2008; Monadjem et al., 2010a). Apart from being barely significant $(P<0.05)$ for clutteredge feeders, it had no impact on open-air feeders or bats generally. This may indicate that the riparian habitat was not an independent control for macadamia orchards. Since orchards comprised rows of trees of at least $3 \mathrm{~m}$ in height, the vegetation structure was not that different from adjacent riparian savannah habitats and bats may have perceived them as being very similar, at least in terms of providing cover for clutter-edge feeders. We do not currently have any data on insect communities in the respective habitats to explain detailed patterns of bat habitat use from this perspective. However, the fact that seasonal differences in bat activity were more pronounced in the orchards compared with the riparian habitat reinforces the notion that seasonal peaks in pest insect availability may be important.

Future studies will include dietary analyses (using faecal pellet dissection and molecular methods) of a wide range of bat species and will conduct insect trapping in parallel with bat acoustic recordings and collections of faecal samples to assess insect availability and hence selectivity of bat foraging. Radio-tracking studies should also be conducted to determine movement patterns of particular species of bats in an agricultural landscape dominated by subtropical fruits in the Levuvhu Valley; a likely candidate for this study is the Heteroptera-specialist, Pipistrellus hesperidus (Monadjem et al., 2010b) which is considered likely to feed on stinkbugs. Increasing local bat populations (e.g. by bat houses) may prove to be an effective and less environmentally destructive means of controlling insects pests than simply increasing chemical pesticide use which may ultimately prove counterproductive if populations of beneficial top insects predators like insectivorous spider, bats and birds decline through poisoning (Wickramasinghe et al., 2003; Pocock \& Jennings, 2008).

\section{Acknowledgements}

The study was funded by a Niche-Area Grant of the University of Venda as well as a National Research Foundation (NRF) Grant for Incentive Funding of Rated Researchers. We are grateful to the Subtropical Fruit Growers Association and Southern African Macadamia Growers Association, SAMAC (particularly Stephanie Roberts and Gerhard Nortje) for funding, and to many other macadamia and avocado-growers who have shown keen interest in bats and offered support for this project. We are grateful to Dries Alberts for the use of weather data from his farm and Alan Whyte for the use of pheromone trap data from his farm. The following fourth-year students and interns from University of Venda assisted with field work: S. E. Khethani, D. Mkhari, L. Sinngu, T. Mukhwevho, P. Nemudivhiso, E. I. Netshipale and V. Mphethe. 


\section{References}

Bohmann, K., Monadjem, A., Noer, C.L., Rasmussen, M., Zeale, M.R.K., Clare, E., Jones, G., Willerslev, E. \& Gilbert, M.T.P. (2011) Molecular diet analysis of two African free-tailed bats (Molossidae) using high throughput sequencing. PLoS ONE 6, e21441. doi:10.1371/journal.pone.0021441.

Boyles, J.G., Cryan, P.M., McCracken, G.F. \& Kunz, T.H. (2011) Economic importance of bats in agriculture. Science 332, 41-42. Cleveland, C.J., Frank, J.D., Federico, P. \& Gomez, I. (2006) Economic value of the pest control service provided by Brazilian free-tailed bat in south-central Texas. Front. Ecol. Environ. 4, 238-243.

Fenton, M.B., Cumming, D.H.M., Rautenbach, I.L., Cumming, G.S., Cumming, L.S., Ford, G., TaYlor, D.R., Dunlop, J., Hovorka, M.D., Johnston, D.S., Portfors, C.V., Kalcounis, M.C. \& Mhlanga, Z. (1998) Bats and the loss of tree canopy in African woodlands. Conserv. Biol. 12, 399-407.

Gannon, W.L., Sherwin, R.E. \& Hayamond, S. (2003) On the importance of articulating assumptions when conducting acoustic studies of habitat use by bats. Wildlife Soc. B. 31, 45-61.

van HoEf J.M. \& Boveng P.L. (2007) Quasi-poisson vs. negative binomial regression: how should we model overdispersed count data? Ecology 88, 2766-2772.

Ironside, D.A. (1981) Insect pests of Macadamia. Queensland Department of Primary Industry, Brisbane.

Jones, V.P. \& CAPRIO, L.C. (1992) Damage estimates and population trends of insects attacking seven macadamia cultivars in Hawaii. J. Econ. Entomol. 85, 1884-1890.

Jones, V.P. \& CAPRIO, L.C. (1994) Southern Stinkbug (Heteroptera: Pentatomidae) feeding on Hawaiian macadamia nuts: the relative importance of damage occurring in the canopy and on the ground. J. Econ. Entomol. 87, 431-435.

Jones, V.P., Delate, K. \& Tome, C.H.M. (1992) Macadamia IPM: where did all this damage come from? Proc. Hawaii. Macadamia Nut Assoc. 32, 48-56.

Jones, G., Jacobs, D.S., Kunz, T.H., Willig, M.R. \& Racey, P.A. (2009) Carpe noctem: the importance of bats as bioindicators. Endang. Species Res. 8, 93-115.

KalKa, M.B., Smith, A.R. \& KalKo, E.K.V. (2008) Bats limit arthropods and herbivory in a tropical forest. Science 320, 71.

Kunz, T.H., De Torrez, E.B., Bauer, D., Lobova, T. \& Fleming, T.H. (2011) Ecosystem services provided by bats. Ann. N.Y. Acad. Sci. 1223, 1-38.

McCracken, G.F., Westbrook, J.K., Brown, V.A., Eldridge, M., Federico, P. \& KunT, T.H. (2012) Bats track and exploit changes in insect pest populations. PLOS ONE 7, e43839.doi:10.1371/ journal.pone.0043839.

Meyer, C.F.J., SchWARZ, C.J. \& FAHR, J. (2004) Activity patterns and habitat preferences of insectivorous bats in a West African forest-savanna mosaic. J. Trop. Ecol. 20, 397-407.

Milne, D.J., Armstrong, M., Fisher, A., Flores, T. \& Pavey, C.R. (2004) A comparison of three survey methods for collecting bat echolocation calls and species-accumulation rates from nightly Anabat recordings. Wildl. Res. 31, 57-63.

Monadjem, A. \& Reside, A. (2008) The influence of riparian vegetation on the distribution and abundance of bats in an African savanna. Acta Chiropterologica 10, 339-348.

Monadjem, A., Reside, A. \& LumsDEn, L. (2007) Echolocation calls of rhinolophid and hipposiderid bats in Swaziland. S. Afr. J. Wildl. Res. 37, 9-15.

Monadjem, A., Ellstrom, M., Maldonaldo, C. \& Fasel, N. (2010a) The activity of an insectivorous bat Neoromicia nana on tracks in logged and unlogged forest in tropical Africa. Afr. J. Ecol. 48, 1083-1091.

Monadjem A., Taylor P.J., Cotterill F.P.D. \& Schoeman M.C. (2010b) Bats of Southern and Central Africa: A Biogeographic and Taxonomic Synthesis. University of Witwatersrand Press, Johannesburg.

Mucina L. \& Rutherford M.C. (2006) The vegetation of South Africa, Lesotho and Swaziland, Vol. 19. South African National Biodiversity Institute, Pretoria.

Naidoo, S., Mackey, R.L. \& Schoeman, M.C. (2011) Foraging ecology of insectivorous bats (Chiroptera) at a polluted and an unpolluted river in an urban landscape. Durban Museum Novitates 34, 21-28.

Noer, C.L., Dabelsteen, T., Bohmann, K. \& Monadjem, A. (2012) Molossid bats in an African agro-ecosystem select sugarcane fields as foraging habitat. Afr. Zool. 47, 1-11.

O'Farrell, M.J., Miller, B.W. \& Gannon, W.L. (1999) Qualitative identification of free-flying bats using the ANABAT detector. J. Mammal. 80, 11-23.

Pocock, M.J.O. \& Jennings, N. (2008) Testing biotic indicator taxa: the sensitivity of insectivorous mammals and their prey to the intensification of lowland agriculture. J. Appl. Ecol. 45, 151160.

Schomman, M.C. (2006) The relative influence of competition and coevolution on the community structure of insectivorous bats in southern Africa. Phd Thesis, University of Cape Town.

Schomman M.C. \& Jacobs D.S. (2008) The relative influence of competition and prey defences on the phenotypic structure of insectivorous bat ensembles in southern Africa. PLOS ONE 3, e3715. doi:10.1371/journal.pone.0003715.

Schomman, M.C. \& JACoBs, D.S. (2011) The relative influence of competition and prey defences on the trophic structure of animalivorous bat ensembles. Oecologia 166, 493-501.

Schomman, M.C. \& Waddington, K.J. (2011) Do deterministic processes influence the phenotypic patterns of animalivorous bat ensembles at urban rivers?. Afr. Zool. 46, 288-301.

Schoeman, P.S. \& Mohlala, R. (in press) Prediction of ideal spraying dates for the stink bug and nut borer complexes. South African Macadamia Assoc. Yearbook. 18.

Schoeman, M.C., Cotterill, F.P.D., Taylor, P.J. \& Monadjem, A. (in press) Using potential distributions to explore environmental correlates of bat species richness in southern Africa: effects of model selection and taxonomy. Curr. Biol. 
Skatak, S.L., Sherwin, R.E. \& Brigham, R.M. (2012) Sampling period, size and duration influence measures of bat species richness from acoustic surveys. Methods Ecol. Evol. 3, $490-502$.

Taylor, P.J., Mkhari, D., Mukwevho, T., Monadjem, A., Schoeman, M.C., Schomman, C. \& Steyn, J.N. (2012) Bats as potential biocontrol agents in an agricultural landscape, Levubu Valley, Limpopo Province: diet, activity and species composition of bats in macadamia orchards and neighbouring natural habitats. South African Avocado Growers' Association Yearbook 34, 5I-6I.

Vincent, P.J., Westcott, D.M., Finson, N.N. \& Nishimoto, R.K. (2001) Relationship between community structure and Southern Green Stink Bug (Heteroptera: Pentatomidae) damage in macadamia nuts. Environ. Entomol. 30, 1028-1035.
Wickramasinghe, L.P., Harris, S., Jones, G. \& Vaughan N. (2003) Bat activity and species richness on organic and conventional farms: impact of agricultural intensification. J. Appl. Ecol. 40 , $984-993$.

Wirliams-GumLen, K. \& Perfecto, I. (2011) Ensemble composition and activity levels of insectivorous bats in response to management intensification in coffee agroforestry systems. PLoS ONE 6, e16502.

Willams-Guluén, K., Perfecto, I. \& Van der Meer, J. (2008) Bats limit insects in a Neotropical agroforestry ecosystem. Science 320,70 . 